\title{
Citrate selective electrodes for the flow injection analysis of soft drinks, beers and pharmaceutical products
}

\author{
Cristina M.F. Ribeiro, Cristina Delerue Matos, M. Goreti F. Sales, M. Carmo V.F. Vaz
}

\begin{abstract}
Aiming the establishment of simple and accurate readings of citric acid (CA) in complex samples, citrate (CIT) selective electrodes with tubular configuration and polymeric membranes plus a quaternary ammonium ion exchanger were constructed. Several selective membranes were prepared for this purpose, having distinct mediator solvents (with quite different polarities) and, in some cases, p-tert-octylphenol (TOP) as additive. The latter was used regarding a possible increase in selectivity. The general working characteristics of all prepared electrodes were evaluated in a low dispersion flow injection analysis (FIA) manifold by injecting 500, I of citrate standard solutions into an ionic strength (IS) adjuster carrier $\left(10^{-2} \mathrm{moll}^{-1}\right)$ flowing at

$3 \mathrm{ml} \mathrm{min}{ }^{-1}$. Good potentiometric response, with an average slope and a repeatability of $61.9 \mathrm{mV}$ per decade and $\pm 0.8 \%$, respectively, resulted from selective membranes comprising additive and bis(2-ethylhexyl)sebacate (bEHS) as mediator solvent. The same membranes conducted as well to the best selectivity characteristics, assessed by the separated solutions method and for several chemical species, such as chloride, nitrate, ascorbate, glucose, fructose and sucrose. Pharmaceutical prepa- rations, soft drinks and beers were analyzed under conditions that enabled simultaneous $\mathrm{pH}$ and ionic strength adjustment

$\left(\mathrm{pH}=3.2\right.$; ionic strength $\left.=10^{-2} \mathrm{moll}^{-1}\right)$, and the attained results agreed well with the used reference method (relative error < 4\%). The above experimental conditions promoted a significant increase in sensitivity of the potentiometric response, with a supra-Nernstian slope of $80.2 \mathrm{mV}$ per decade, and allowed the analysis of about 90 samples per hour, with a relative standard deviation $<1.0 \%$.
\end{abstract}

Keywords: Flow injection analysis; Citrate selective electrodes; Polymeric membranes; Potentiometry

\section{Introduction}

Citric acid (CA) presents an antibacterial effect and well as a $\mathrm{pH}$ controlling property [1], for which it is ex- tensively used upon food industries. It is also utilized within the pharmaceutical field because of its anticoag- ulant and antacid properties, and for preventing kidney calculi as well [2]. This wide use of CA, connected to the complexity of the concerned sample matrices, has motivated researchers for the establishment of several chemical strategies regarding quantification of CA.

Connected with several kinds of detection systems, complexation with metal ions is a widely used approach for the determination of CA in soft drinks and pharmaceuticals. Its complex with $\mathrm{Cu}$ (II) is the basis, until now, of several proposals in literature. In a sim- ple way, an excess of copper is made to react with the analyte and the remaining metal ion is determined by either atomic absorption spectrometry [3] or titration with EDTA [4]. Alternatively, a titration procedure 
with copper is established in stationary [5] or in flow conditions [6], having a copper selective electrode for detection. The latter regards a flow injection analy- sis (FIA) system, for which it is more adequate for routine and repetitive determinations of $C A$.

Complexation with iron(III), monitored at $490 \mathrm{~nm}$, is also reported in literature [7]. The previous com-plex is the basis of an indirect determination of CA as well, regarding a competitive complex formation

with $\left[\mathrm{Fe}(\mathrm{SCN})_{2}\right]^{+}$, a colored complex of maximum absorbance at $460 \mathrm{~nm}$ [8]. Similarly, CA is determined by its inhibitory effect upon the $\mathrm{Fe}(\mathrm{III})$ catalytic ox- idation of 1,4-diaminophenol by $\mathrm{H}_{2} \mathrm{O} 2$, thus reduc- ing the $500 \mathrm{~nm}$ absorbance of the oxidation product [9]. The formation of a tertiary complex with $\mathrm{Fe}$ (III) and ohydroxyquinolphthalein, monitored at $610 \mathrm{~nm}$, is also proposed, presenting, however, severe interfer- ences from several kinds of acids [10].

The ability of CA to interfere with other chemi- cal systems thus promoting changes at the recorded analytical signal has been exploited as well. Accord- ingly, CA is determined by means of fluoride and lead selective electrodes due to its inhibitory effect upon the growth of calcium fluoride [11] and lead carbonate [12] seed crystals. The latter, concern- ing the precipitation of CA and lead(II), has also been the basis of an atomic absorption spectropho- tometric quantification of the analyte, coupled to the FIA technique [13]. The enhancement of CA on the chemiluminescence light emission after reac-

tion of tris-(2,2 -bipyridine)ruthenium and $\mathrm{Ce}(\mathrm{IV})$ is other approach for determination of the same analyte [14].

Overall, all previously described methods require chemical transformation of CA to enable detection and subsequent quantification. For this, many compounds present in complex samples may give rise to analyti- cal errors, particularly those which react with CA or compete with it for a same reaction. In addition, the described methods are somewhat elaborate, an inade- quate feature for the routine determinations required by industries. They involve a high number of manip-ulations by an operator that may conduct to random errors, and to unnecessary exposition to toxic com- pounds as well. Moreover, most soft drinks and phar- maceuticals present color and/or suspended particles, which can promote analytical errors if associated to optical techniques.
Other strategies in literature concern the redox properties of CA. Depending on the experimental conditions and by means of photochemical induction, CA reduces $\mathrm{Fe}(\mathrm{III})$ to $\mathrm{Fe}(\mathrm{II})$. The latter is subse- quently monitored by UV-Vis, if complexed with 1,10phenanthroline $[15,16]$, or by luminescence, if made to react with luminol [17]. Due to the slow kinetics of the former reaction, these methods present low sampling throughput, even when connected to stop-flow conditions $[16,17]$. Furthermore, the pres- ence of other reducing compounds among real sam- ples, such as ascorbic acid, interfere with the analytical results. Without requiring chemical transformation of the analyte, CA is directly determined by polarography with a dropping copper amalgam electrode [18,19]. However, interfering compounds like phosphate hin- der the possibility of a prompt analysis of samples.

Due to the non-existence of a selective detection for CA, as well as to the interferences recorded at the formerly described methods, many proposals in literature have pondered the use of enzymes. By reaction with citrate (CIT) lyase and oxaloacetate decarboxy- lase, the analyte is converted into pyruvic acid, which is subsequently determined by differential pulse polarography [20]. Alternatively, pyruvic acid is made to react with pyruvate oxidase for a succeeding ampero- metric quantification [21-23]. Other similar methods resort to CIT lyase and malate/lactate dehydrogenase enzymes, and are connected to the UV-Vis quantifi- cation of nicotinamide adenine dinucleotide (NADH) [24,25]. Considering the high selectivity of enzymes towards a substrate, this strategy permits minimiza- tion of interferences. Furthermore, enzymes are im- mobilized in a reactor [22-25] or at the surface of an electrode [21] in order to prevent their high con- sumption. However, because enzymes are costly, react slowly, and require a frequent replacement, applica- tion of these methods turns out to be expensive and slow.

Alternatively, separative techniques can be found in literature, specifically chromatography coupled to UV $[26,27]$ or refractive index [28] detectors. Usu- ally, they do not suffer from interference of foreign compounds, even without a prior chemical treatment of samples and regarding that a good resolution is at- tained. However, not all cited methods allow eliminat- ing sample pretreating steps [27]. Furthermore, they become quite expensive taking into account the high 
quality of the concerned reagents and the time required for degassing and filtration procedures.

Consequently, the main purpose of the present work is to establish a low cost direct reading of CA, without requiring previous chemical transformation of the analyte or separation procedures, enabling the quick and easy attainment of analytical results. To accomplish this purpose, several CIT selective electrodes with polymeric membranes will be here proposed. Consid- ering that industries require expeditious and regular determinations, these detectors will be constructed un- der a tubular configuration and applied into a FIA sys- tem. Possibility of application to the analysis of soft drinks and pharmaceuticals will be exploited later.

\section{Experimental}

\subsection{Apparatus}

The potential differences between the indicating and the reference electrode were measured by means of a Crison , $\mathrm{pH} 2002$ decimilivoltammeter ( $\pm 0.1 \mathrm{mV}$ sen- sitivity) coupled to a Kipp \& Zonen BD 111 recorder. An Orion, 90-

00-29, double-junction electrode was used as reference. The selective electrodes, with no internal reference solution, were made tubular and were constructed as described by Alegret et al. [29]. Measurements of $\mathrm{pH}$ were made by means of a Sentek 71728 combined glass electrode.

The FIA system comprised a Gilson Minipuls 3 peristaltic pump, fitted with poly(vinyl chloride) (PVC) tubing (1.85 mm i.d.) and a four-way Rheo- dyne 5020 injection valve. All components were connected by PTFE tubing (Omnifit, Teflon, $0.8 \mathrm{~mm}$ i.d.), Gilson end-fittings and connectors. The support devices for tubular and reference electrodes as well as the ground electrode were constructed as described by Alegret et al. [30].

For degassing samples, a Bandelin, Sonorex, RK $100 \mathrm{H}$ ultrasonic bath was used.

\subsection{Reagents and solutions}

All chemicals were of analytical grade and deion- ized water (conductivity $<0.1, \mathrm{~S} \mathrm{~cm}^{-1}$ ) was used.

Trisodium citrate dihydrate ( $\mathrm{Na3} \mathrm{CIT}$, Riedel-de- Haën), sodium sulfate (Fluka), o-phosphoric acid
(85\%, Merck) and potassium dihydrogenphosphate (Riedel-deHaën) were used throughout. For the selec- tive membrane preparation, bis(triphenylphosphoranyliden)ammonium (BTPPIA) chloride (Aldrich), bis (2ethylhexyl)sebacate (bEHS, Fluka), o-nitrophenyl octyl ether (oNFOE, Fluka), p-tert-octylphenol (TOP, Fluka), PVC of high molecular weight (Fluka) and tetrahydrofuran (THF, Riedel-deHaën) were em- ployed. For evaluating the effects of both $\mathrm{pH}$ and interfering ionic species, sodium hydroxide (Merck), concentrated sulfuric acid (Merck), potassium chlo- ride (Merck), potassium nitrate (Riedel-deHaën),

$\mathrm{I}-(+)$-ascorbic acid sodium salt (Riedel-deHaën), d-(+)glucose (Merck), d-(-)-fructose (Merck) and (+)-sucrose (Merck) were selected.

The ionic strength (IS) was adjusted to $10^{-2} \mathrm{moll}^{-1}$

by means of a $3.3 \times 10^{-3} \mathrm{~mol} \mathrm{I}^{-1} \mathrm{Na}_{2} \mathrm{SO}_{4}$ solution. The simultaneous $\mathrm{pH}$ and ionic strength adjustment was attained with a $\mathrm{H}_{3} \mathrm{PO}_{4} / \mathrm{NaH}_{2} \mathrm{PO}_{4}$ buffer solution with a $3.2 \mathrm{pH}$ and a $2 \times 10^{-2} \mathrm{~mol} \mathrm{I}^{-1}$ IS.

Apart from the other chemicals, each carrier solu- tion included $1 \times 10^{-6} \mathrm{~mol} \mathrm{I}^{-1}$ of $\mathrm{Na} \mathrm{ClT}$, to enable both baseline stabilization and preservation of the selective membrane. All standard solutions injected into the manifold were prepared by accurate dilution of a $1.0 \times 10^{-1} \mathrm{moll}^{-1}$ stock solution of $\mathrm{Na} 3 \mathrm{CIT}$ in either IS or $\mathrm{pH}$ and IS adjuster solutions.

The effect of $\mathrm{pH}$ was studied for a $10 \times 10^{-2} \mathrm{~mol} \mathrm{I}^{-1}$ $\mathrm{Na} 3 \mathrm{CIT}$ solution. Interference from other chemicals was determined by the separated solutions method [31], for which $1.0 \times 10^{-3}, 5.0 \times 10^{-3}$ and $1.0 \times$ $10^{-2}$ moll $^{-1}$ solutions of $\mathrm{Na} 3 \mathrm{ClT}$ and potassium chloride, potassium nitrate, sodium ascorbate, sucrose, glucose or fructose were prepared. These solutions were all made in $3.3 \times 10^{-4} \mathrm{~mol} \mathrm{I}^{-1} \mathrm{Na} 2 \mathrm{SO}_{4}$.

\subsection{Comparison methods}

Results of potentiometric analyses of foodstuffs were compared with those obtained by the Boehringer test [32] based on enzymatic reactions. CA was converted to oxaloacetate and acetate in a reaction catalyzed by CIT lyase. In the presence of I-malate dehydrogenase and Ilactate dehydrogenase enzymes both oxaloacetate and its decarboxylation product (pyruvate) were reduced to Imalate and I-lactate, respectively, by reduced NADH. The amount of $\mathrm{NADH}$ oxidized is stoichiometric with the amount of 
$\mathrm{CIT}$, and NADH is monitored by its absorbance at 340 $\mathrm{nm}$.

Results of analysis of pharmaceuticals were com- pared with those obtained by following the United States Pharmacopoeia (USP) procedures [33]. Since USP does not mention a specific procedure for each of the pharmaceutical forms analyzed, sodium CIT and sodium CIT/CA oral solution monographs were used for the granulated powder (with 99.8\% of a complex of hexapotassium hexasodium pentacitrate hydrate) and for the irrigation gel, respectively. The latter consists of an acid-base titration, having $\mathrm{NaOH}$ as titrant and phenolphthalein as end-point indicator. The last one is similar requiring previous extraction of interfering compounds.

\subsection{Construction of CIT selective electrodes}

The anionic exchanger, BTPPIA-CIT, was prepared by a precipitation reaction between $100 \mathrm{ml}$ of a $1 \times 10^{-2} \mathrm{~mol}$ $\mathrm{I}^{-1} \mathrm{Na} 3 \mathrm{ClT}$ aqueous solution and $100 \mathrm{ml}$ of a $1 \times 10^{-2} \mathrm{~mol}$ $\mathrm{I}^{-1}$ BTPPIA chloride aqueous solu-

tion. The resulting precipitate was filtered, thoroughly washed with water, dried, and kept in a dark flask in- side a dessicator to prevent alterations caused by light and humidity.

Types A and B sensor solutions were prepared by dissolving $0.040 \mathrm{~g}$ of the ionic sensor and $0.220 \mathrm{~g}$ of TOP in $2.00 \mathrm{~g}$ of oNFOE or bEHS, respectively. Types C and D sensor solutions were prepared similarly, but without TOP. The corresponding membranes, whose compositions are indicated in Table 1, were prepared by mixing $0.4 \mathrm{ml}$ of the sensor solutions with $0.180 \mathrm{~g}$ of PVC in approximately $4 \mathrm{ml}$ of THF.

Each membrane solution was added to a tubular conductive support mainly composed of graphite and epoxy resin [29]. The selective electrodes so obtained

Table 1

Overall membrane composition (\%, w/w) of CIT selective elec- trodes

\begin{tabular}{lcccc}
\cline { 2 - 4 } Components & $\mathrm{A}$ & $\mathrm{B}$ & $\mathrm{C}$ & $\mathrm{D}$ \\
\hline BTPPIA-CIT & 1.3 & 1.3 & 1.3 & 1.3 \\
oNFOE & 61.0 & - & 67.0 & - \\
bEHS & - & 60.6 & - & 66.8 \\
TOP & 6.6 & 6.5 & - & - \\
PVC & 31.1 & 31.6 & 31.7 & \\
\hline
\end{tabular}

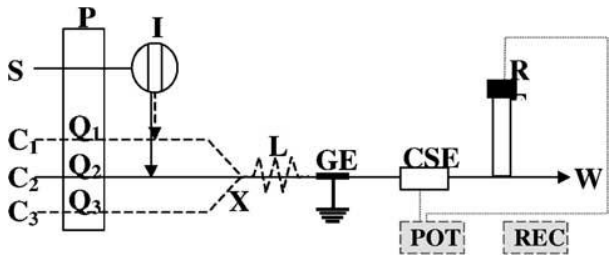

Fig. 1. Flow injection manifold for studying the characteristics of the potentiometric response (channel C2) and for the analy- sis of real samples (channels C1 and (3). P: peristaltic pump; S:

sample; $\mathrm{C} 1$ : water; $\mathrm{C} 2$ : sodium sulfate $\left(\mathrm{IS}=10^{-2} \mathrm{~mol}\right.$ $\mathrm{I}^{-1}$ ) with $1 \times 10^{-6} \mathrm{~mol} \mathrm{I}^{-1}$ of $\mathrm{Na3} \mathrm{CIT}$; $\mathrm{C} 3$ : phosphate buffer $\left(\mathrm{pH}=3.2\right.$ and $\left.\mathrm{IS}=2 \times 10^{-2} \mathrm{~mol} \mathrm{I}^{-1}\right)$ with $2 \times 10^{-6}$ $\mathrm{moll}^{-1}$ of Na3CIT; I: injec- tion valve $(500, \mathrm{l}) ; Q 1=Q 2=$ Q3: $3 \mathrm{ml} \mathrm{min}^{-1} ; \mathrm{X}$ : confluence

point; L: mixing coil $(30 \mathrm{~cm})$; GE: grounding electrode; CSE: CIT

selective electrode; R: reference electrode; W: waste; POT: dec- imilivoltammeter; REC: recorder. Overall flow rate of $6 \mathrm{ml} \mathrm{min}^{-1}$.

were called types A, B, C and D according to the sensor solution they contain.

\subsection{Procedures}

The overall working characteristics of the tubu-lar CIT selective electrodes were evaluated with a singlechannel FIA manifold (Fig. 1, channel C2), having as carrier the IS adjuster. The injection volume was of 500,1 and the flow rate was $3 \mathrm{ml} \mathrm{min}^{-1}\left(\mathrm{Q}_{2}\right)$. For simultaneous $\mathrm{pH}$ and IS adjustment the potentio- metric response was recorded with a double-channel FIA manifold (Fig. 1, channels $C_{1}$ and $\left.C_{3}\right)$, having as carriers water $\left(C_{1}\right)$ and phosphate buffer (C3). This last solution had an IS value double that of the IS adjuster solution as it was diluted by half at the confluence point (Fig. 1, X).

The selectivity study was made by separately inject- ing 500 , I of $\mathrm{Na} 3 \mathrm{CIT}$ solution and other possible inter-

fering compound solutions into a single-channel FIA manifold with a carrier stream of $3.3 \times 10^{-4} \mathrm{~mol} \mathrm{I}^{-1}$ $\mathrm{Na} 2 \mathrm{SO} 4$, flowing at $3 \mathrm{mlmin}^{-1}$.

The effect of $\mathrm{pH}$ on the potentiometric response was evaluated by injecting into the single-channel flow manifold a $5.0 \times 10^{-4} \mathrm{~mol} \mathrm{I}^{-1} \mathrm{Na} 3 \mathrm{CIT}$ solution, prepared in $3.3 \times 10^{-4} \mathrm{~mol} \mathrm{I}^{-1} \mathrm{Na}_{2} \mathrm{SO}_{4}$. A small adaptation of the manifold consisting of a closed

loop with continuous circulation of $200 \mathrm{ml}$ of CIT standard solution was required. The $\mathrm{pH}$ of this so-lution was altered by small additions of saturated 
$\mathrm{NaOH}$ solution and concentrated $\mathrm{H}_{2} \mathrm{SO}_{4}$, and was monitored by an additional potentiometric cell consisting of a combined glass electrode connected to a decimilivoltammeter. The selection of specific so- lutions for assessing the effect of different $\mathrm{pHs}$ was designed to prevent both the significant change of the CIT concentration and the introduction of other chemical species into the system (other than those already present: $\mathrm{Na}^{+}, \mathrm{SO}_{4}{ }^{2-}$ and $\mathrm{CIT}$ ). For each $\mathrm{pH}$ used, an amount of $500, \mathrm{l}$ was inserted into a 3 $\mathrm{ml} \mathrm{min}{ }^{-1}$ carrier stream of $3.3 \times 10^{-4} \mathrm{moll}^{-1} \mathrm{Na}_{2} \mathrm{SO}_{4}$.

A wide range of real samples, including soft drinks, beers and pharmaceutical preparations, was selected in order to demonstrate the applicability of the pro-posed system. Soft drinks and beers were degassed by sonication. The pharmaceutical preparations included here were a granular powder and an irrigation gel. The first contained $99.8 \%$ of a complex of hexapotas- sium hexasodium pentacitrate hydrate and the latter $9 \%$ of sodium CIT, and were prepared for potentio- metric analysis by dissolving and diluting them with water. Because of the linear wide response range of the potentiometric system, and with the exception of the pharmaceuticals, all samples were analyzed with- out modification, in a double-channel flow manifold. Prior to analysis the potentiometric system was cal-ibrated under optimum FIA conditions: $500, \mathrm{I}$ and

$Q_{1}=Q_{3}=3 \mathrm{ml} \mathrm{min}^{-1}$ (Fig. 1), allowing a flow rate of $6 \mathrm{ml}$ $\min ^{-1}$ at thedetector.

\section{Results and discussion}

In order to prepare CIT selective electrodes with suitable working characteristics, four kinds of poly- meric membranes were first prepared. These mem- branes differed in the plasticizers used (ONFOE or bEHS) and in the presence/absence of additive (TOP). Apart from different chemical structures the plasticiz- ers presented very different polarity characteristics: oNFOE has a dielectric constant of 23.6 and bEHS of

4.6 [34]. The presence of additive (TOP) in selective membranes is intended to increase selectivity proper- ties by establishing hydrogen bonds [35]. To confirm this, only two of the four membranes had additive (types $A$ and $B)$. The common point within the pre- pared membranes was the ionic exchanger, BTPPIA chloride. This compound was first used for isolation and precipitation of labile organometallic anions [36] and after applied as counter ion in liquid membrane electrodes due to its high lipophilicity [37]. Presently, this exchanger has been applied as well in polymeric matrix and comparison with another kind of quater- nary ammonium salt gave rise to wider analytical concentration range electrodes, as a consequence of a significant decrease in the lower limit of linear range [38]. Selection of the above-mentioned ion exchanger regarded therefore these results.

The behavior of each CIT selective electrode was assessed, so that the best ones could be selected for the analysis of real samples.

\subsection{Working characteristics of CIT selective electrodes under adjusted IS}

The working characteristics of the CIT selective electrodes were evaluated in a single-channel FIA manifold (Fig. 1). The selection of a 500,1 injec-tion volume and of a $3 \mathrm{ml} \mathrm{min}$-1 flow rate allowed the establishment of experimental conditions close to the equilibrium state. Results obtained during IS ad-justment indicated a higher sensitivity for both types $A$ and $B$ electrodes (Table 2), suggesting that a low polarity solvent, as well as TOP, could improve the characteristics of the detector.

The influence of $\mathrm{pH}$ on the potentiometric response was studied with standard and carrier solutions pre- pared at a lower concentration of $\mathrm{Na}_{2} \mathrm{SO}_{4}$ than those used for IS adjustment since the potentiometric re- sponse recorded here could be a result of interference of both $\mathrm{pH}$ and $\mathrm{SO}_{4}{ }^{2-}$. Absence of electrolyte in the carrier was impossible since potential readings were very unstable due to an inadequate electrical contact between indicating and reference electrodes. The results obtained showed a similar behavior for all electrodes. While an increase in $\mathrm{pH}$ produced an increase in the analytical signal, indicating a $\mathrm{HO}^{-}$interference, the decrease of $\mathrm{pH}$ had the opposite ef- fect. Operational $\mathrm{pH}$ ranges were quite narrow and were found to be within 2-4 units, where potential

changes were of the order of $\pm 6 \mathrm{mV}$ (Table 2). As can be seen in Table 2, the $\mathrm{pH}$ range is even smaller

with membranes comprising additive, which dissoci- ates to phenolate ion, $\mathrm{a} \mathrm{H}^{+}$exchanger that would also be present within the membrane [39]. 
Table 2

Working characteristics of CIT selective electrodes with IS adjustment or $\mathrm{pH}$ and IS adjustment

\begin{tabular}{|c|c|c|c|c|c|c|}
\hline \multirow[t]{2}{*}{ Working characteristics } & \multicolumn{3}{|c|}{$\mathrm{IS}=10^{-2} \mathrm{~mol}$} & \multirow[b]{2}{*}{$\mathrm{D}$} & \multicolumn{2}{|c|}{$\mathrm{pH}=3.2$ and $\mathrm{IS}=10^{-2} \mathrm{moll}^{-1}$} \\
\hline & $A$ & B & $\mathrm{C}$ & & $A$ & B \\
\hline $\begin{array}{l}\text { LLLR (mol I-1)a } \\
\text { Slope (mV per decade) }\end{array}$ & $\begin{array}{l}5 \times 10^{-5} \\
51.4 \pm 1.4\end{array}$ & $\begin{array}{l}5 \times 10^{-5} \\
61.9 \pm 0.4\end{array}$ & $\begin{array}{l}5 \times 10^{-5} \\
11.5 \pm 1.5\end{array}$ & $\begin{array}{l}5 \times 10^{-5} \\
34.5 \pm 1.2\end{array}$ & $\begin{array}{l}5 \times 10^{-5} \\
64.2 \pm 0.7\end{array}$ & $\begin{array}{l}5 \times 10^{-5} \\
80.2 \pm 0.7\end{array}$ \\
\hline $\begin{array}{l}\text { Repeatability }( \pm \mathrm{mV})^{\mathrm{b}} \\
R^{<}\end{array}$ & $\begin{array}{l} \pm 0.6(1.1 \%) \\
>0.9984\end{array}$ & $\begin{array}{l} \pm 1.1(0.8 \%) \\
>0.9980\end{array}$ & $\begin{array}{l} \pm 0.4(1.6 \%) \\
>0.9935\end{array}$ & $\begin{array}{l} \pm 0.6(1.7 \%) \\
>0.9980\end{array}$ & $\begin{array}{l} \pm 1.1(0.7 \%) \\
>0.9989\end{array}$ & $\begin{array}{l} \pm 1.2(0.6 \%) \\
>0.9989\end{array}$ \\
\hline Sampling rate $\left(\mathrm{h}^{-\perp}\right)$ & 80 & 89 & 86 & 89 & 90 & 95 \\
\hline $\mathrm{pH}$ working range $\mathrm{e}^{\mathrm{C}}$ & $2.0-3.5$ & $2.0-3.5$ & $2.0-4.0$ & $2.0-4.0$ & - & - \\
\hline
\end{tabular}

\footnotetext{
a Lower limit of linear range.

b At $5.0 \times 10^{-3} \mathrm{moll}^{-1}$.

c At $5.0 \times 10^{-4} \mathrm{moll}^{-1}$.
}

The interference of other compounds in CIT determinations was also evaluated. As in the $\mathrm{pH}$ study, all solutions were prepared in $3.3 \times 10^{-4} \mathrm{moll}^{-1} \mathrm{Na}_{2} \mathrm{SO}_{4}$. Potentiometric selectivity coefficients were calculated for a concentration of $5.0 \times 10^{-3} \mathrm{~mol} \mathrm{I}^{-1}$ for several compounds (Table 3 ). When the degree of ionization was unknown, it was considered that analytical sig- nals resulted from a -1 charge anion, assuming there- fore the highest possible interference. For inorganic species, $\mathrm{NO}_{3}{ }^{-}$ was generally the one with the high- est potentiometric selectivity coefficientsrepresenting

a huge interference in types $\mathrm{C}$ and D CIT selective electrodes. Among organic compounds, carbohydrates (glucose, fructose and sucrose) were those represent- ing the lowest (non-significant) interference, mainly concerning types A and B membrane. The interference of ascorbate varied significantly for the four types of electrodes, showing its lowest effect for the type B membrane. Generally, the overall behavior of all electrodes confirmed the great importance of TOP within the membranes for the attainment of adequately selective electrodes.

Since the potentiometric detectors C and D showed poor working characteristics as well as inadequate selectivity, these electrodes were not used for further trials.

\subsection{Optimization of the FIA set-up}

Injection volume and flow rate influence in the single-line flow manifold was first evaluated. The optimization was multivariate, checking the analytical signals produced for a 100, 200, 500 and 1000 , I sampling, at 2, 4, 6 and $8 \mathrm{ml} \mathrm{min}^{-1}$ flow rates. Recordings from each previous condition were mainly evalu- ated in terms of dispersion, for which $5.0 \times 10^{-4}$, $1.0 \times 10^{-3}$ and $5.0 \times 10^{-3} \mathrm{~mol} \mathrm{I}^{-1} \mathrm{Na3ClT}$ standard solutions were selected. A low dispersion could be obtained at every flow rate tested when a sample vol- ume $\geq 500$, I was inserted into the manifold. As a

Table 3

Potentiometric selectivity coefficients of CIT selective electrodes

\begin{tabular}{lllll}
\hline Interference & \multicolumn{1}{l}{ IS $\left(10^{-2} \mathrm{~mol} \mathrm{I}^{-1}\right)$} & & $\mathrm{C}$ \\
\cline { 2 - 5 } & $\mathrm{A}$ & $\mathrm{B}$ & $-1.51 \pm 0.42$ & $\mathrm{D}$ \\
\hline Chloride & $-1.60 \pm 0.24$ & $-2.68 \pm 0.07$ & $-0.92 \pm 0.01$ \\
Nitrate & $-2.26 \pm 0.04$ & $-1.22 \pm 0.04$ & $-3.11 \pm 0.23$ & $+1.89 \pm 1.38$ \\
Ascorbate & $-1.73 \pm 0.09$ & $-3.05 \pm 0.01$ & $-1.24 \pm 0.12$ & $-1.65 \pm 0.37$ \\
Glucose & $-2.19 \pm 0.05$ & $-2.53 \pm 0.01$ & $-1.70 \pm 0.16$ \\
Fructose & $-2.64 \pm 0.87$ & $-2.67 \pm 0.29$ & $-2.26 \pm 0.15$ & $-1.44 \pm 0.06$ \\
Sucrose & $-2.16 \pm 0.02$ & $-2.01 \pm 0.37$ & $-2.00 \pm 0.15$ & $-1.32 \pm 0.11$ \\
\hline
\end{tabular}

\footnotetext{
a $5.0 \times 10^{-3} \mathrm{moll}^{-1}$.
} 
compromise between sensitivity, sample volume and sampling rate, conditions selected from this study were a 500, I volume and an overall flow rate of $6 \mathrm{ml} \mathrm{min}^{-1}$. Under these conditions, dispersion was insignificant and the analytical signal was $>96 \%$ of the equilibrium state.

In order to enable the automatic adjustment of both $\mathrm{pH}$ and IS of samples, a double-channel flow mani- fold was further considered. Keeping the experimental conditions previously selected, the length of a heli- cally coiled reactor (L, Fig. 1) responsible for a good mixing of confluent solutions, was varied from 15 to $50 \mathrm{~cm}$. A length of $30 \mathrm{~cm}$ was chosen because shorter path lengths gave lower and less reproducible analyt- ical signals and longer ones lengths gave a reduced sampling rate.

\subsection{Working characteristics of CIT selective electrodes under adjusted $\mathrm{pH} / \mathrm{IS}$}

Working characteristics of both types A and B selective electrodes were further evaluated in a si- multaneous $\mathrm{pH}$ and IS adjustment experiment, under a double-channel FIA manifold and using the previ- ously selected experimental conditions. Comparing the results of trials under IS adjustment, the findings recorded here indicated a significant improvement in the potentiometric characteristics, mainly concerning sensitivity (Table 2). An improvement at the lower limit of linear range was recorded as well considering that sample plug was diluted by half at the confluence point ( $X$, Fig. 1 ).

It was interesting to note that the slope of the type $B$ electrode was much higher than predicted by the Nernst-Nikolski equation. Even though there is no obvious theoretical explanation, this could have been a result of three carboxilate groups being present in the chemical structure of CIT.

\subsection{Application to real samples}

Under the optimized FIA set-up, 14 samples of different kinds of soft drinks, beers and pharmaceu- ticals were analyzed and the potentiometric results were compared with those obtained from an adequate comparison method [32,33]. Samples were injected into a system using type B electrodes as the detec-tor and their concentrations were interpolated from a

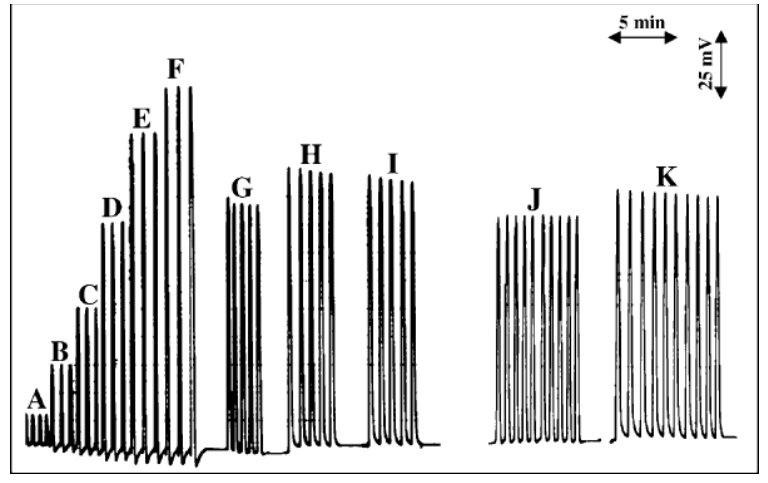

Fig. 2. FIA diagrams of the determination of $\mathrm{CIT}$ in real sam- ples (G-I) preceded by calibration (A: $2.0 \times 10^{-4}$ mol I-1; B: $5.0 \times 10^{-4} \mathrm{moll}^{-1}$; C: $1.0 \times 10^{-3} \mathrm{moll}^{-1}$; D: 2.0 $\times 10^{-3} \mathrm{moll}^{-1}$;

$\mathrm{E}: 5.0 \times 10^{-3} \mathrm{~mol} \mathrm{I}^{-1} ; \mathrm{F}: 1.0 \times 10^{-2} \mathrm{~mol} \mathrm{I}^{-1}$ ), as well as the re-

peatability of the sample readings ( $\mathrm{J}$ and $\mathrm{K}$ ).

calibration curve for $1.0 \times 10^{-4}$ to $1.0 \times 10^{-2} \mathrm{~mol} \mathrm{I}^{-1} \mathrm{CIT}$ (Fig. 2). The mean results of five determinations

obtained from separate runs and using each of the two methodologies are given in Table 4, along with the corresponding standard deviations. Relative deviation (RD) between the two methods was <4\% (Table 4). Using the mean values obtained from FIA $(C F)$ and comparison methods $\left(C_{R}\right)$, the following regression

line was established: $C F=1.0052 \times C_{R}-0.0194$.

Results from the irrigation gel were excluded because of its high concentration. Comparison of the two methods demonstrated very good agreement as is shown by the insignificant displacement of the origin (0.0194), the slope (1.0052) and the squared correlation coefficient $\left(R^{2}=0.9966\right)$.

Considering as null hypothesis that the two methods agree, a paired two-tail test for $5 \%$ level of significance gave a calculated $t$ (0.998) below the tabulated one (t0.025,13 = 2.160), thus allowing the null hypothesis. Comparison of variances obtained for each sample was made by F-test using the same assumptions as for Student's $t$-test, and calculated values (Table 4) were always below the critical $F$-value $(F 0.025(44)=9.60)$, thus again confirming the null hypothesis.

Repeatability of the FIA method was lower than $1 \%$ assessed by calculating relative standard deviation of 10 consecutive injections of samples (Fig. 2). Sam- pling rates were about 90 samples per hour when real samples were injected. 
Table 4

Determination of CIT in soft drinks and pharmaceuticals by the proposed FIA system and comparison method, along with the corresponding relative deviation (RD) and calculated F-value

\begin{tabular}{|c|c|c|c|c|}
\hline \multirow[t]{2}{*}{ Samples } & \multicolumn{2}{|c|}{$\mathrm{CIT}\left(\times 10^{-3} \mathrm{~mol} \mathrm{I}^{-1}\right)$} & \multirow[t]{2}{*}{$\mathrm{RD}(\%)$} & \multirow[t]{2}{*}{$F$-test } \\
\hline & $\mathrm{FIA}$ & Comparison & & \\
\hline Soft drink 1 & $3.72 \pm 0.16$ & $3.75 \pm 0.17$ & -0.9 & 1.16 \\
\hline Soft drink 2 & $3.39 \pm 0.02$ & $3.51 \pm 0.03$ & -3.5 & 1.58 \\
\hline Soft drink 3 & $2.75 \pm 0.04$ & $2.86 \pm 0.06$ & -3.8 & 2.12 \\
\hline Soft drink 4 & $2.82 \pm 0.05$ & $2.75 \pm 0.04$ & +2.5 & 1.11 \\
\hline Soft drink 5 & $2.46 \pm 0.05$ & $2.38 \pm 0.04$ & +3.4 & 1.25 \\
\hline Soft drink 6 & $3.86 \pm 0.08$ & $3.74 \pm 0.06$ & +3.2 & 1.82 \\
\hline Soft drink 7 & $2.92 \pm 0.12$ & $2.83 \pm 0.14$ & +3.0 & 1.41 \\
\hline Soft drink 8 & $4.30 \pm 0.16$ & $4.45 \pm 0.20$ & -3.4 & 1.60 \\
\hline Soft drink 9 & $6.89 \pm 0.22$ & $6.64 \pm 0.20$ & +3.8 & 1.25 \\
\hline Soft drink 10 & $7.42 \pm 0.04$ & $7.54 \pm 0.06$ & -1.6 & 2.12 \\
\hline Beer (with alcohol) & $0.752 \pm 0.034$ & $0.766 \pm$ & -1.8 & 3.12 \\
\hline Beer (with no alcohol) & $1.82 \pm 0.07$ & $1.88 \pm 0.09$ & -3.2 & 1.56 \\
\hline Pharmaceutical (powder) & $0.620 \pm 0.025$ & $0.644 \pm$ & -3.7 & 1.34 \\
\hline Pharmaceutical (irrigation) & $455 \pm 16$ & $440 \pm 35$ & +3.4 & 4.90 \\
\hline
\end{tabular}

\section{Conclusions}

CIT selective electrodes with polymeric membranes incorporating bEHS and TOP gave adequate response characteristics, particularly with respect to sensitivity and selectivity. These features enabled the establish-ment of a simple FIA system, as well as direct and expeditious determinations of CIT in different kinds of matrices. Additionally, the wide linear range of the potentiometric response made possible quantification of CIT without requiring any sample dilution for al- most all the samples tested.

The proposed system is simple, accurate and inexpensive, in both reagent consumption and equipment involved. It is therefore suitable for routine procedures.

\section{References}

[1] R.J. Lewis, Food Additive Handbook, Van Nostrand Reinhold, New York, 1989.

[2] E.L. Péres, A. Rios, N. Valcárcel, Anal. Chim. Acta 366 (1998) 231.

[3] L. Che, J. Wang, J. Liu, L. Zhang, Fenxi-Huaxue 18 (1990) 575.

[4] E. Szekely, Talanta 32 (1985) 153.

[5] A. Olin, B. Wallen, Anal. Chim. Acta 151 (1983) 65.

[6] J.L.F.C. Lima, C.D. Matos, M.C.V.F. Vaz, J. Silva, Fresenius' J. Anal. Chem. 364 (1999) 266.

[7] X.R. Wang, Fenxi-Huaxue 25 (1997) 165.
[8] A. Krug, R. Kellner, Mikrochim. Acta 113 (1994) 203.

[9] D.G. Themelis, P.D. Tzanavaras, Anal. Chim. Acta 428 (2001) 23.

[10] Y. Fujita, I. Mori, K. Fujita, T. Tanaka, Eisei Kagaku 33 (1987) 56.

[11] F. Grases, A.C. Bauza, J.G. March, Analyst 116 (1991) 59.

[12] F. Grases, C. Genestar, Talanta 38 (1991) 1353.

[13] M.C. Yebra, R.M. Cespon, Fresenius' J. Anal. Chem. 365 (1999) 370.

[14] Z.K. He, H. Gao, L.J. Yuan, S.F. Lu, H. Meng, X.Y. Li, Y.

Zeng, Talanta 47 (1998) 301.

[15] Z.L. Wang, L.F. Wang, Y.L. Liu, J.Z. Li, Fenxi-Huaxue 24 (1996) 1331.

[16] E.L. Perez, A. Rios, M. Valcarcel, Anal. Chim. Acta 366 (1998) 231.

[17] T.P. Ruiz, C.M. Lozano, V.Tomas, O. Val, Analyst 120 (1995) 471.

[18] A.S. Perez, J.H. Mendez, J.A.G. Barez, Food Chem. 32 (1989) 69.

[19] A.S. Perez, J.H. Mendez, J.A.G. Barez, Stud. Chem. Univ. Salamanca 9 (1984) 269.

[20] K. Hasebe, S. Hikima, T. Kakizaki, H. Yoshida, Fresenius' J. Anal. Chem. 333 (1989) 19.

[21] M.I. Prodomidis, S.M.T. Karayannis, M.I. Karayannis, P.M. Vadgama, Analyst 122 (1997) 1101.

[22] K. Matsumoto, T. Tsukatani, Anal. Chim Acta 321 (1996) 157.

[23] K. Matsumoto, T. Tsukatani, Y. Okajima, Electroanalysis 7 (1995) 527. 
[24] British Standards Institution, British Standard EN, vol. 1137, 1995, p. 12.

[25] M. Planta, F. Lazaro, R. Puchades, A. Maquieira, Analyst 118 (1993) 1193. 
[26) (1996) 835.

[27] E. Burke, S.R. Zimmerman, D.S. Brown, D.R. Jenke, J. Chromatogr. Sci. 26 (1988) 527.

[28] R.W. Chong, B.J. Moore, J. Chromatogr. A 692 (1995) 203.

[29] S. Alegret, J. Alonso, J. Bartroli, P.M. Paulis, J.L.F.C. Lima,

A.A.S.C. Machado, Anal. Chim. Acta 164 (1984) 147. [30] S. Alegret, J. Alonso, J. Bartroli, A.A.S.C. Machado, J.L.F.C. Lima, P.M. Paulis, Quim. Anal. 6 (1987) 278.

[31] W.E. Van der Linden, International Union of Pure and Applied Chemistry, Pure Appl. Chem. 66 (1994) 2527.

[32] UV-method for the determination of citric acid in Foodstuffs, Boehringer Mannheim, Cat. No. 139076, 1997.
[33] United States Pharmacopoeia XXIV, The National Formulary IX, Official Monographs, Sodium Citrate Monograph, and Sodium Citrate and Citric Acid Oral Solution Monograph, 2000, p. 1531.

[34] T. Okada, H. Sugihara, K. Hiratani, Analyst 120 (1995)

2381. [35] H. Hara, S. Okazaki, T. Fujinaga, Anal. Chim.

Acta 121

(1980) 119.

[36] P. Oltmanns, D. Rehder, J. Organometall. Chem. 345 (1988) 87.

[37] R. Aubeck, C. Brauchle, N. Hampp, Analyst 116 (1991)

811. [38] M.C.B.S.M. Montenegro, M.G.F. Sales, J. Pharm. Sci. 89

(2000) 876.

[39] H. Hara, Y. Kondoh, O. Mitani, S. Okazaki, Anal. Chem. 62 (1990) 1139. 